\title{
Primary Graft Dysfunction After Heart Transplantation
}

\author{
Hong Chee Chew • Gayathri Kumarasinghe • Arjun Iyer • Mark Hicks • Ling Gao • \\ Aoife Doyle • Andrew Jabbour • Kumud Dhital • Emily Granger • Paul Jansz • \\ Christopher Hayward • Anne Keogh • Eugene Kotlyar • Phillip Spratt • Peter Macdonald
}

Published online: 4 September 2014

(C) Springer International Publishing AG 2014

\begin{abstract}
Primary graft dysfunction (PGD) is a lifethreatening complication of heart transplantation that presents as left, right, or biventricular dysfunction occurring within the first 24 hours of transplant surgery for which there is no identifiable secondary cause. Myocardial injury caused by acute catecholamine toxicity and the release of multiple proinflammatory mediators in the donor, followed by ischaemiareperfusion injury sustained during retrieval, have been considered the predominant pathogenetic processes leading to PGD. Donor, recipient, and procedural factors contribute to the development and severity of the clinical syndrome. The changing donor and recipient characteristics over the last two decades, particularly the increasing donor and recipient age, have led to heightened risk of PGD. PGD is graded from mild to severe depending on the extent of circulatory support that is required to maintain haemodynamic stability and vital organ function. While advances in acute mechanical support devices have improved the outlook for patients with PGD, the rate of mortality remains high for those with severe PGD, reaching $40 \%$. Potential approaches to preventing or minimising the
\end{abstract}

H. C. Chew · G. Kumarasinghe · A. Iyer · M. Hicks $\cdot$ L. Gao •

A. Doyle $\cdot$ A. Jabbour $\cdot$ K. Dhital $\cdot$ E. Granger $\cdot$ P. Jansz $\cdot$

C. Hayward · A. Keogh • E. Kotlyar P. Spratt • P. Macdonald $(\triangle)$

Heart \& Lung Transplant Unit, St Vincent's Hospital, Sydney,

Victoria Street, Darlinghurst, NSW 2010, Australia

e-mail: pmacdonald@stvincents.com.au

H. C. Chew $\cdot$ G. Kumarasinghe $\cdot$ A. Iyer $\cdot$ M. Hicks $\cdot$ L. Gao $\cdot$ A. Doyle · A. Jabbour $\cdot$ K. Dhital $\cdot$ E. Granger $\cdot$ P. Jansz $\cdot$

C. Hayward · A. Keogh $\cdot$ E. Kotlyar · P. Spratt $\cdot$ P. Macdonald

Victor Chang Cardiac Research Institute, Sydney, Darlinghurst, NSW, Australia

H. C. Chew $\cdot$ G. Kumarasinghe $\cdot$ A. Iyer $\cdot$ M. Hicks $\cdot$ L. Gao $\cdot$ A. Doyle $\cdot$ A. Jabbour $\cdot$ K. Dhital $\cdot$ E. Granger $\cdot$ P. Jansz $\cdot$

C. Hayward · A. Keogh $\cdot$ E. Kotlyar · P. Spratt $\cdot$ P. Macdonald

University of New South Wales, Sydney, NSW 2052, Australia severity of PGD include optimising donor management, donor heart preservation, and donor/recipient matching.

Keywords Donormanagement · Ischemia reperfusion injury · Biomarkers · Organ preservation · Vasoplegia

\section{Introduction}

Heart transplantation is now well established as the most effective therapy available to treat refractory end-stage heart failure. Improvements in immunosuppression have dramatically improved short- and long-term survival; however, transplant recipients still face a $5 \%$ to $10 \%$ risk of mortality within the first month post-transplant due to early failure of the allograft. In some recipients, this is due to identifiable causes such as hyperacute rejection or pre-existing pulmonary hypertension. In the majority of cases, however, the primary cause is severe myocardial injury sustained prior to and during transplantation, a condition known as primary graft dysfunction (PGD). Unfortunately, the lack of a clear definition of PGD has made it difficult, if not impossible, to ascertain the true incidence of this condition. For example, in the most recent report of the ISHLT registry, 30-day and 90-day mortality for the more than 100,000 recipients transplanted since 1982 were $10 \%$ and $14 \%$, respectively [1, $2 \bullet \cdot$. Two-thirds of deaths within the first month were attributed to either 'graft failure' or 'multi-organ failure' $[1,2 \cdot \bullet]$. It is likely that the large majority of these early deaths were due to PGD.

The reported incidence and outcomes of PGD have varied markedly among individual centres $[3-5,6 \bullet, 7-10,11 \bullet]$. Some of this variability may reflect real differences (possibly reflecting different policies regarding donor and recipient acceptance criteria), but a more likely explanation for the inter-institutional variability is the use of different diagnostic criteria for PGD among centres. Recently, following a 
workshop convened by the International Society of Heart \& Lung Transplantation, a consensus definition and grading system was established for PGD. This is a critical first step in establishing the true incidence of PGD and its impact on post-transplant morbidity and mortality. The purpose of this review is to highlight recent advances in our understanding of what is meant by the term PGD, its pathophysiology, and clinical risk factors. We also review current recommendations for prevention and treatment of this life-threatening condition.

\section{Definition and Grading of Primary Graft Dysfunction}

The recently established consensus definition of PGD is the onset of left, right, or biventricular dysfunction occurring within the first 24 hours of transplant surgery for which there is no identifiable secondary cause. PGD may range from mild to severe depending on the extent of myocardial dysfunction and haemodynamic compromise, as well as the extent of myocardial support required to maintain haemodynamic stability and perfusion of vital organs. Another term in common usage is primary graft failure (PGF). Although not separately defined, PGF corresponds to severe PGD in the new grading system. The grading system of PGD is summarised in Table 1 (adapted from Kobashigawa et al. [2••]).

Exclusion criteria include any secondary causes that can produce a similar clinical presentation (e.g., hyperacute rejection, pulmonary hypertension, and cardiac tamponade) $[2 \bullet \bullet]$.

\section{Incidence}

As previously mentioned, there has been a marked variation in the reported incidence of PGD among studies from individual centres, ranging from $2 \%$ to $26 \%[3-5,6 \bullet, 7-10,11 \bullet]$, largely due to inconsistencies in the definition for PGD used by different authors. In a large retrospective study of the United Network of Organ Sharing (UNOS) database, Russo et al. reported the incidence of PGF at $2.5 \%$ [10]; however, the authors defined PGF as postoperative death or retransplantation within the first 90 days of transplant, indicating that only the most severe cases were included in the analysis. It is expected that with a standardised definition of PGD, future studies will more accurately reflect the true incidence of PGD. An important caveat is that as centres increasingly utilise 'marginal' or 'extended criteria' donors, there is a trend among some surgeons to 'rest' the transplanted heart on ECMO or other temporary mechanical support for periods of 24 hours or longer rather than attempt immediate weaning from cardiopulmonary bypass in the operating room. The rationale here is to allow the heart more time to recover from the perioperative stresses that it has been subjected to before imposing the further stress of supporting the recipient circulation. Hence, if mechanical circulatory support is used as a diagnostic criterion for severe PGD, this policy could lead to an over-estimation of its incidence.

\section{Aetiology and Pathogenesis}

The aetiology and pathogenesis of PGD have been extensively covered in recent reviews $[2 \bullet \bullet, 12]$. At every step in the transplant pathway, from the onset of brain death to weaning of the heart from cardiopulmonary bypass in the recipient, the heart is subjected to repeated insults. Historically, it has been believed that the predominant pathogenetic process leading to the development of PGD was myocardial injury caused by acute catecholamine toxicity and the release of multiple

Table 1 Definition and Grading of Primary Graft Dysfunction [2••]

\begin{tabular}{|c|c|c|c|}
\hline Grade & Left or Biventricular & Right Ventricular & Support \\
\hline Mild & $\begin{array}{l}\mathrm{RA}>15 \mathrm{mmHg}, \mathrm{PAW}>20 \mathrm{mmHg} \\
\quad \mathrm{CI}<2.01 / \mathrm{min} / \mathrm{m}^{2} \text { (lasting }>1 \text { hour) } \\
\text { Or } \\
\text { LVEF } 40-50 \%\end{array}$ & $\begin{array}{l}\mathrm{RA}>15 \mathrm{mmHg}, \text { PAWP }<15 \mathrm{mmHg}, \\
\quad \mathrm{CI}<2.01 / \mathrm{min} / \mathrm{m}^{2} \\
\text { Plus } \\
\text { TPG }<15 \mathrm{mmHg} \text { and } / \text { or PA Sys }<50 \mathrm{mmHg}\end{array}$ & Low-dose inotropic infusion \\
\hline Moderate & $\begin{array}{l}\mathrm{RA}>15 \mathrm{mmHg}, \text { PAW }>20 \mathrm{mmHg}, \\
\quad \mathrm{CI}<2.01 / \mathrm{min} / \mathrm{m}^{2}, \mathrm{MAP}<70 \mathrm{mmHg} \\
\quad \text { (lasting }>1 \text { hour) } \\
\text { Or } \\
\mathrm{LVEF}<40 \%\end{array}$ & $\begin{array}{l}\mathrm{RA}>15 \mathrm{mmHg}, \mathrm{PAWP}<15 \mathrm{mmHg} \text {, } \\
\quad \mathrm{CI}<2.0 \mathrm{1} / \mathrm{min} / \mathrm{m}^{2}, \mathrm{MAP}<70 \mathrm{mmHg} \\
\quad \text { (lasting }>1 \mathrm{hour} \text { ) } \\
\text { Plus } \\
\mathrm{TPG}<15 \mathrm{mmHg} \text { and } / \text { or PA Sys }<50 \mathrm{mmHg}\end{array}$ & $\begin{array}{l}\text { High-dose inotropic support (inotrope score }>10 \text { ) } \\
\text { Or } \\
\text { IABP }\end{array}$ \\
\hline Severe & $\begin{array}{l}\text { As above } \\
\text { Plus } \\
\text { LVAD or BiVAD (e.g., ECMO) }\end{array}$ & $\begin{array}{l}\text { As above } \\
\text { Plus } \\
\text { RVAD }\end{array}$ & Mechanical circulatory support beyond IABP \\
\hline
\end{tabular}

Inotrope Score: dopamine $(\times 1)+$ dobutamine $(\times 1)+$ amrinone $(\times 1)+$ milrinone $(\times 15)+$ epinephrine $(\times 100)+$ norepinephrine $(\times 100)$ with each drug dosed in $\mathrm{mcg} / \mathrm{kg} / \mathrm{min}$

(Adapted with permission from Kobashigawa J, Zuckermann A, Macdonald P, Leprince P, Esmailian F, Luu M, et al. Report from a consensus conference on primary graft dysfunction after cardiac transplantation. The Journal of Heart and Lung Transplantation: The Official Publication of the International Society for Heart Transplantation. 2014 Apr;33(4):327-40. PubMed PMID: 24661451) [2••] 
proinflammatory mediators in the donor, followed by ischaemia-reperfusion injury sustained during retrieval and transport [13-15, 16•, 17, 18]. More recently, the importance of recipient determinants has been emphasised [11•]. Activation of systemic inflammatory response syndrome (SIRS) and development of vasoplegic syndrome in the recipient have also been identified as potential contributors to the development of PGD [19].

\section{Risk Factors for PGD}

Multiple risk factors have been identified for the development of PGD [3, 6• 7-10, 11•, 16•, 22-24, 26]. Broadly, these can be grouped into donor, procedural, and recipient factors, as summarised in the Table 2. Despite the recognition that the donor characteristics listed in Table 1 are associated with an increased risk of adverse outcomes post-transplant, the scarcity of 'standard criteria' donor organs has placed increasing pressure on heart transplant programs to utilise these 'marginal' or 'extended criteria' donor hearts. In addition, the success of heart transplantation as a treatment for endstage heart disease has resulted in a progressive increase in the acceptance criteria for heart transplantation, particularly in relation to recipient age. Patients accepted for heart transplantation are not only older but also have higher rates of comorbidity. Moreover, an increasing proportion of patients waiting for heart transplantation are reliant on mechanical circulatory support. These trends were highlighted in the most recent report of the International Society for Heart and Lung Transplantation Registry [1]. The increasing prevalence of risk factors for PGD, particularly donor and recipient age, is the most likely explanation for the continuing high rate of PGD in recent ISHLT registry reports.

A number of authors have highlighted the additive adverse impact when multiple risk factors for PGD are present. In a large UNOS registry analysis, Russo et al. reported a negative interaction between increasing donor age and ischaemic time with regard to post-transplant survival [16•]. In that review, hearts from donors less than 20 years of age appeared to tolerate ischaemic times beyond six hours with no adverse impact on post-transplant survival, whereas hearts from donors older than 33 years demonstrated reduced survival when ischaemic time increased beyond 3.5 hours. In another study from the Cardiac Transplant Research Database Group, Stehlik et al. reported that donor recipient weight differences interacted with age and gender [27]. In that study, weight differences of up to $30 \%$ did not affect survival so long as the donor was 30 years or younger. Donor and recipient gender further modified the degree of risk.

Recently, Segovia and colleagues developed a predictive risk score for PGD based on six different variables, each of which independently increased the risk of PGD approximately twofold in their derivation study population [11•]. They included four recipient variables, one donor variable, and one procedural variable to derive a RADIAL risk score, as follows: recipient Right atrial pressure $>10 \mathrm{mmHg}$, recipient Age $>60$ years, Diabetes and Inotrope dependence, donor Age $>30$ years, and Length of ischaemic time $>240$ minutes. In a subsequent validation study, they assigned one point for each risk factor and stratified heart transplant recipients into low-risk (0-1), intermediate-risk (2), and high-risk $(>3)$ groups based on the RADIAL score [28]. Moderate or severe PGD developed in approximately $10 \%$ in the low-risk group, in approximately $20 \%$ of the intermediate group, and almost $30 \%$ of the high-risk group. Although a high RADIAL risk score was clearly associated with increased risk of PGD, a major constraint, as noted by the authors, was the limited predictive power when applied to individual patients (as opposed to group data), as exemplified by the fact that most patients in the high-risk group did not develop PGD. Another potential limitation was the low use of VAD support in both

Table 2 Risk Factors for Primary Graft Dysfunction

\begin{tabular}{lll}
\hline Donor Factors & Procedural Factors & Recipient Factors \\
\hline - Increasing donor age & $\bullet$ Ischaemic time & ・ Increasing recipient age \\
- Cause of death & $\bullet$ Donor/recipient mismatching & - Inotrope dependence \\
$\quad$ - Spontaneous ICH & $\bullet$ Gender mismatching & Ventilator support \\
- Carbon monoxide & - Female donor/male recipient & Mechanical circulatory support \\
- Echocardiographic abnormalities & $\bullet$ Concomitant lung retrieval & Pulmonary hypertension \\
- Systolic dysfunction & & - Comorbidities \\
- Left ventricular hypertrophy & & - Diabetes mellitus \\
- High inotropic requirements & & - Morbid obesity \\
- Comorbidities & & - Renal disease \\
- Diabetes mellitus & &
\end{tabular}

See text for details and references; $I C H$ intracranial haemorrhage

(Data adapted from: Iyer A, Kumarasinghe G, Hicks M, Watson A, Gao L, Doyle A, et al. Primary graft failure after heart transplantation. Journal of Transplantation. 2011;2011:175768. PubMed PMID: 21837269. PubMed Central PMCID: 3151502) [12] 
the derivation and validation studies, raising a question regarding the applicability of the RADIAL score in VADsupported transplant recipients. Regardless of these limitations, however, the RADIAL risk score provides an excellent example of the cumulative risk of PGD in the presence of combined donor, procedural, and recipient risk factors.

\section{Biomarkers of Primary Graft Dysfunction}

There has been longstanding interest in the identification of readily measureable biomarkers in the donor that might predict PGD. A variety of potential biomarkers have been examined, but studies have yielded contradictory results, and the usefulness of biomarkers for this indication remains controversial. The most commonly studied biomarker is troponin (either troponin I or T), which is a highly sensitive marker of myocyte necrosis [29-32]. Studies in patients suffering subarachnoid haemorrhage or Takotsubo cardiomyopathy have demonstrated a significant association between serum troponin levels and myocardial dysfunction. However, these same studies have also shown that myocardial dysfunction is reversible, even in the presence of elevated troponin levels [33, 34]. Similarly, multiple studies in potential heart donors have demonstrated a significant correlation between the level of troponin I (or T) in donor serum and donor heart dysfunction, although the relationship between donor troponin levels and PGD has been inconsistent among studies [29-32]. Some studies have reported that donor troponin levels were predictive of PGD, whereas others found this not to be the case. A potential confounder in the interpretation of these studies is that serum troponin levels in donors whose hearts were not used were higher than levels in donors whose hearts were transplanted, and it is unclear whether knowledge of the troponin level influenced the decision not to transplant the heart. BNP or NT-proBNP is another easily measureable serum biomarker that is a sensitive indicator of myocardial dysfunction. As with troponin, several authors have reported a significant correlation between elevated serum BNP (or NTproBNP) in the donor and donor heart dysfunction; however, there has been an inconsistent relationship between donor BNP and post-transplant graft function [35-38].

Other authors have examined levels of proinflammatory mediators in donor serum. Examples include CRP, TNF $-\alpha$, IL-6 and procalcitonin (PCT) [39]. Of these, donor PCT was found to correlate most closely with donor heart dysfunction and non-use of a donor heart [39]. In another study, Aharinejad et al. identified SMARCAL1 from a protein array and demonstrated that serum levels of this molecule in the donor were strongly predictive of PGD [40]. Although simple commercial assays have been developed for PCT and SMARCAL1, they are not widely utilised, and it is unclear whether the results would be available in time to influence clinical decision-making. Several studies have suggested that a combination of biomarkers may be more effective than single-molecule assays in predicting PGD [32, 41]. However, further studies are needed to establish whether any single biomarker or combination of biomarkers can reliably distinguish between donor hearts that will function well posttransplant and those that will fail.

\section{Management}

The management of PGD primarily involves haemodynamic support to maintain perfusion while allowing the transplanted heart time to recover. In mild cases, low-dose inotropic support is the only therapy required. By definition, moderate cases require high-dose inotropic support (total inotrope score $>10$ ) or intra-aortic balloon pump support. In severe cases, mechanical support in combination with pharmacological therapy is required to support the circulation until myocardial recovery occurs or to permit retransplantation $[2 \bullet \bullet]$.

The role of novel pharmacological therapies in addition to standard inotropic support is uncertain. In one small uncontrolled study, levosimendan $(0.1 \mu \mathrm{g} / \mathrm{kg} / \mathrm{min})$ was given to 12 patients with PGD, defined as an LV ejection fraction of less than $30 \%$. Following a 24-hour infusion, levosimendan improved ejection fraction and cardiac output, and patients showed a rapid reduction of the required dose of inotropic medications [42]. No patient required mechanical support, and 30-day survival in this series was $93 \%$. Subsequent three-year follow-up, however, revealed very high late mortality [43]. In addition, the vasodilator action of levosimendan is likely to prevent its use in patients with severe PGD, who are usually profoundly hypotensive in the absence of any vasopressor support [44].

Mechanical support device options include VA extracorporeal membrane oxygenation (ECMO) support, acute LVAD, BiVAD, and RVAD support, depending on the type of PGD. Early reports describing the use of older mechanical devices such as the ABIOMED BVS 500, Bio-Medicus, and Thoratec VAD to treat severe PGD highlighted the high rate of complications and high mortality (up to $80 \%$ ) associated with their use [45]. Improvements in membrane and pump design have led to renewed enthusiasm for the use of ECMO as a mechanical bridge for a range of indications, including severe PGD. The greatest degree of experience of ECMO support for PGD comes from D'Alessandro et al., who reported the outcomes of ECMO support in 91 patients with severe PGD between 2003 and 2008 [6•]. The authors noted that $60 \%$ of patients were able to be weaned from support, with $46 \%$ surviving to discharge and $39 \%$ surviving to one year post-transplant [ $6 \bullet$. Marasco et al. reported 10 survivors in a group of 15 patients with severe PGD requiring ECMO support [3]. Similarly, Listijono et al. reported 30-day and six-month survival of 
$82 \%$ among 17 patients with PGD on ECMO support [8]. In both of these studies, the authors emphasised the importance of early institution of ECMO, often prior to leaving the operating room, before the onset of multi-organ failure.

Several novel and smaller percutaneous mechanical circulatory support systems have been developed to provide shortterm circulatory support. These include the Levitronix CentriMag, Impella, and TandemHeart devices. The largest share of experience with any of these newer devices has been with the Levitronix CentriMag. A multicentre UK registry analysis of the use of this device to support 38 patients with severe PGD between 2003 and 2008 reported 30-day survival of $50 \%$ and one-year survival of $32 \%$ [46], outcomes very similar to those reported by D'Alessandro et al. with ECMO [6•]. Experimental comparisons among Impella, TandemHeart, and ECMO have shown more effective haemodynamic support with ECMO when applied to animals with ventricular fibrillation [47]. Clinical studies have suggested similar outcomes when these devices are applied to patients with post-infarction or cardiomyopathy-associated cardiogenic shock, but there is limited experience with the newer devices in severe PGD [48]. When applied as an RVAD for acute RV failure, ECMO appears to perform better than RVAD [49], but as is the case with left-sided mechanical support, further comparative studies are needed.

\section{Outcomes}

As mentioned previously, the absence of a universally accepted definition of PGD has made it difficult to estimate not only its incidence, but also its impact on survival. Current data from the ISHLT transplant registry reveals that two-thirds of deaths that occur in the first 30 days after transplant are due to 'graft failure' or 'multi-organ dysfunction'. Most of these events are probably the result of fatal PGD [2••].

Aliabadi et al. compared survival of 1,238 patients with PGD and PGF between two time periods (period 1, 19841999; period 2, 2000-2011), in which they broadly defined PGD as patients requiring high inotropic support and PGF as patients requiring mechanical support. The authors reported an overall incidence of $9 \%$ for PGD and $6 \%$ for PGF. While the incidence of PGD declined in the more recent era, the incidence of PGF trebled, from $3 \%$ to $9 \%$. Reported survival at 30 days and one year was $65 \%$ and $58 \%$, respectively, in PGD group and $51 \%$ and $35 \%$, respectively, in PGF group. In a comparison of survival in each group based on time periods, there was no significant change in survival in the PGD group but a significant improvement in the PGF group (period 1, $24 \%$ vs. period 2, $63 \%$ ) [50].

Similarly, Gomez-Bueno et al. reviewed historical trends at their institution in the incidence and outcome of PGD. In a retrospective review of 621 heart transplant patients from
1984 to 2006, they reported an overall incidence of severe PGD of $9 \%$, with 30-day mortality of $80 \%$. Detailed breakdown of data into four time periods revealed a significant increase in severe PGD (12.4\%) in the most recent period, 2000-2006, but lower 30-day mortality (67\%) for the same period [51].

The increasing incidence of severe PGD in the more recent periods reported in these studies is not surprising given the increasing utilisation of 'marginal' donor hearts and the increasing recipient complexity. However, this has been offset by improved survival, most likely related to improvements in the safety of ECMO and other acute circulatory support devices. This, in turn, has encouraged earlier implementation of mechanical circulatory support before the onset of multi-organ failure.

\section{Future Directions and Recommendations}

Given the complexities in the pathogenesis of PGD, it is clear that there will not be a single simple solution to the problem. Rather, a multi-stage strategy that addresses each phase of the organ donation pathway will be needed in order to minimise the risk and impact of PGD.

\section{Donor Management}

Numerous studies have demonstrated that an aggressive donor management policy, incorporating invasive haemodynamic monitoring and optimisation, improves the quality of the donor heart as wells as other transplantable organs, and increases the utilisation of donor hearts for transplantation [52-54]. Hormonal 'resuscitation', including thyroid hormone administration and the use of high-dose steroids, is widely utilised and advocated [55], although there is conflicting evidence regarding its efficacy for this indication $[20,53$, 56•]. Novel approaches such as anti-complement inhibitors have shown promise in experimental models, but clinical trials are needed [21].

\section{Organ Preservation}

Hypothermic Static Storage Currently, most hearts are stored and transported in cold cardioplegic preservation solutions. The formulation of these solutions has been guided by three general principles: i) rapid reduction of metabolic rate of tissue by electromechanical arrest, followed by static storage at $4{ }^{\circ} \mathrm{C}$; ii) provision of a biochemical medium to maintain tissue viability and structural integrity; and iii) prevention of ischaemia-reperfusion injury (IRI). The many commercial and in-house formulations currently in use underscore the complexity of the molecular and cellular mechanisms that underlie IRI, as well as the lack of consensus as to the optimal 
strategy for cardiac preservation [57]. Commercial products such as St Thomas' solution No. 2 (Plegisol), Bretschneider (Custodiol HTK), University of Wisconsin solution (ViaSpan), and Celsior have been in clinical use since the early 1990s [58-62], and provide adequate protection for standard-criteria donor hearts subjected to ischemic times of less than three hours [63]. However, their cardioprotective capacities may be suboptimal for the increasing numbers of marginal donor hearts seen in current clinical practice $[1,16 \bullet$, $27,63]$.

Our own laboratory has investigated supplementation of existing preservation solutions to further enhance their cardioprotective capacity. Recently, we reported that supplementation of the Celsior solution with glyceryl trinitrate (GTN), zoniporide, and erythropoietin (EPO) enhanced cardiac protection in a rat model of donor heart preservation and a porcine heart transplant model $[64,65]$. While translation of this strategy into the clinic has been limited by the nonavailability of a clinically approved $\mathrm{Na}+/ \mathrm{H}+$ exchange inhibitor, early clinical experience with supplementing the Celsior solution with GTN and EPO has yielded encouraging results [66]. Other novel preservation solutions include adenosinelidocaine (AL), a normokalaemic, non-depolarising cardioplegic solution currently employed in paediatric and adult cardiac surgery. Its role in heart preservation is currently being investigated. Results from Dobson et al. showed favourable recovery of cardiac parameters after six hours of cold storage in AL solution [67, 68].

Ex vivo Perfusion A more novel approach to cardioprotection during heart removal and transport has been the use of ex vivo perfusion of the donor heart. Hypothermic and normothermic systems have been developed, with the TransMedics Organ Care System (OCS) now approved for clinical use in a number of jurisdictions. In addition to minimising the ischaemic time to which the donor heart is subjected, normothermic perfusion allows metabolic and functional assessment of the donor heart during transport, thereby enabling identification of hearts with significant disease. Two randomised trials with the OCS device, PROTECT [69] and PROCEED II [70], are ongoing, in which OCS is being compared to cold storage for standardcriteria donors. Preliminary data from both trials have been presented and have demonstrated equivalent short-term outcomes. Arguably, the true potential for ex vivo perfusion is in the recovery of marginal hearts, particularly from older donors who are more susceptible to ischaemic reperfusion injury $[16 \bullet]$.

\section{Recipient Management}

Donor/Recipient Size and Gender Matching Decisions regarding donor/recipient matching are complex and must take into account multiple factors, including donor heart quality, recipient urgency, sensitisation status, relative size and gender of donor and recipient, as well as logistical considerations. As can be seen from Table 2, the only two modifiable risk factors for PGD are donor/recipient size matching and gender matching. Transplantation of undersized donor hearts, particularly small female hearts, into male recipients with elevated pulmonary vascular resistance has been shown in multiple recent UNOS registry analyses to be associated with an increased risk of PGD [71-74]. More accurate donor and recipient sizing, as recently proposed by Reed et al., may help to avoid unforeseen size mismatches, especially for gender mismatched transplants [73]. A similar policy of avoiding undersized marginal hearts in high-risk recipients such as patients maintained on ventilator or acute mechanical support devices may also help minimise the risk of PGD.

SIRS and Vasoplegia Avoidance of risk factors such as prolonged ischaemia and cardiopulmonary bypass times for SIRS and vasoplegia is desirable but not always practicable, particularly in patients who have already undergone one or more complex cardiac operations prior to heart transplant surgery [19]. As yet, there is no proven therapy for the prevention of SIRS and vasoplegia in the setting of cardiopulmonary bypass. Although high-dose corticosteroids are administered routinely before, during, and after heart transplantation to prevent rejection, a recent meta-analysis of corticosteroid administration to prevent SIRS following cardiopulmonary bypass failed to identify any benefit [75]. A number of other drug classes, including statins, have been investigated, but larger studies are needed. For patients with established vasoplegia after cardiopulmonary bypass, methylene blue has been reported to restore responsiveness to vasopressors and improve survival [25].

\section{Conclusions}

Although the incidence of primary graft dysfunction has been difficult to estimate due to the number of definitions applied to this term, it appears that some degree of PGD is common, affecting at least $20 \%$ of heart transplant recipients. Severe PGD or PGF is the leading cause of death in the first month after heart transplantation and also likely accounts for many deaths beyond this period. The introduction of a consensus definition and classification for PGD will allow a more accurate assessment of the true incidence of PGD and its impact on post-transplant outcomes. Based on recent trends in the prevalence of recognised risk factors for PGD, increasing donor and recipient age, in particular, the incidence of PGD is expected to remain high, and potentially increase. Prevention of PGD will require a multi-pronged strategy targeting donor, procedural, and recipient risk factors. Treatment of severe 
PGD remains challenging; however, recent experience with newer mechanical circulatory support devices suggests that the outlook for this life-threatening complication may be improving.

\section{Compliance with Ethics Guidelines}

Conflict of Interest HC Chew, G Kumarasinghe, A Iyer, M Hicks, L Gao, A Doyle, A Jabbour, K Dhital, E Granger, P Jansz, C Hayward, A Keogh, E Kotlyar, P Spratt, and P Macdonald each declare no conflict of interest.

Human and Animal Rights and Informed Consent All studies by H.C. Chew, G. Kumarasinghe, A. Iyer, M Hicks, L. Gao, A. Doyle, A. Jabbour, K. Dhital, E. Granger, P. Jansz, C. Hayward, A. Keogh, E. Kotlyar, P. Spratt, and P. Macdonald involving animal and/or human subjects were performed after approval by the appropriate institutional review boards. Written informed consent, when required, was obtained from all participants.

\section{References}

Papers of particular interest, published recently, have been highlighted as:

- Of importance

•. Of major importance

1. Lund LH, Edwards LB, Kucheryavaya AY, Dipchand AI, Benden $\mathrm{C}$, Christie JD, et al. The registry of the International Society for Heart and Lung Transplantation: thirtieth official adult heart transplant report - 2013; focus theme: age. J Heart Lung Transplant. 2013;32(10):951-64.

2.• Kobashigawa J, Zuckermann A, Macdonald P, Leprince P, Esmailian F, Luu M, et al. Report from a consensus conference on primary graft dysfunction after cardiac transplantation. J Heart Lung Transplant: Off Publ Int Soc Heart Transplant. 2014;33(4): 327-40. This paper summarises the outcome of a workshop on primary graft failure held in 2013. A major outcome of the workshop was a consensus definition of primary graft dysfunction accepted by all stakeholders.

3. Marasco SF, Esmore DS, Negri J, Rowland M, Newcomb A, Rosenfeldt FL, et al. Early institution of mechanical support improves outcomes in primary cardiac allograft failure. J Heart Lung Transplant: Off Publ Int Soc Heart Transplant. 2005;24(12):203742.

4. Lima B, Rajagopal K, Petersen RP, Shah AS, Soule B, Felker GM, et al. Marginal cardiac allografts do not have increased primary graft dysfunction in alternate list transplantation. Circulation. 2006;114(1 Suppl):I27-32.

5. Ibrahim M, Hendry P, Masters R, Rubens F, Lam BK, Ruel M, et al. Management of acute severe perioperative failure of cardiac allografts: a single-centre experience with a review of the literature. Can j Cardiol. 2007;23(5):363-7.

6. D'Alessandro C, Golmard JL, Barreda E, Laali M, Makris R, Luyt $\mathrm{CE}$, et al. Predictive risk factors for primary graft failure requiring temporary extra-corporeal membrane oxygenation support after cardiac transplantation in adults. Eur J Cardiothorac Surg: Off J Eur Assoc Cardiothorac Surg. 2011;40(4):962-9. Largest reported experience to date on the use of ECMO to manage severe PGD.
7. D'Ancona G, Santise G, Falletta C, Pirone F, Sciacca S, Turrisi M, et al. Primary graft failure after heart transplantation: the importance of donor pharmacological management. Transplant Proc. 2010;42(3):710-2.

8. Listijono DR, Watson A, Pye R, Keogh AM, Kotlyar E, Spratt P, et al. Usefulness of extracorporeal membrane oxygenation for early cardiac allograft dysfunction. J Heart Lung Transplant: Off Publ Int Soc Heart Transplant. 2011;30(7):783-9.

9. Oto T, Excell L, Griffiths AP, Levvey BJ, Bailey M, Marasco S, et al. Association between primary graft dysfunction among lung, kidney and heart recipients from the same multiorgan donor. Am J Transplant: Off J Am Soc Transplant Am Soc Transplant Surg. 2008;8(10):2132-9.

10. Russo MJ, Iribarne A, Hong KN, Ramlawi B, Chen JM, Takayama $\mathrm{H}$, et al. Factors associated with primary graft failure after heart transplantation. Transplantation. 2010;90(4):444-50.

11. Segovia J, Cosio MD, Barcelo JM, Bueno MG, Pavia PG, Burgos R, et al. RADIAL: a novel primary graft failure risk score in heart transplantation. J Heart Lung Transplant: Off Publ Int Soc Heart Transplant. 2011;30(6):644-51. First description of a prediction algorithm for $P G D$ that incorporates donor, procedural and recipient risk factors.

12. Iyer A, Kumarasinghe G, Hicks M, Watson A, Gao L, Doyle A, et al. Primary graft failure after heart transplantation. J Transplant. 2011;2011:175768.

13. D'Amico TA, Meyers CH, Koutlas TC, Peterseim DS, Sabiston Jr DC, Van Trigt P, et al. Desensitization of myocardial betaadrenergic receptors and deterioration of left ventricular function after brain death. J Thorac Cardiovasc Surg. 1995;110(3):746-51.

14. Pratschke J, Wilhelm MJ, Kusaka M, Basker M, Cooper DK, Hancock WW, et al. Brain death and its influence on donor organ quality and outcome after transplantation. Transplantation. 1999;67(3):343-8.

15. Pratschke J, Wilhelm MJ, Kusaka M, Hancock WW, Tilney NL. Activation of proinflammatory genes in somatic organs as a consequence of brain death. Transplant Proc. 1999;31(1-2):1003-5.

16. Russo MJ, Chen JM, Sorabella RA, Martens TP, Garrido M, Davies $\mathrm{RR}$, et al. The effect of ischemic time on survival after heart transplantation varies by donor age: an analysis of the United Network for Organ Sharing database. J Thorac Cardiovasc Surg. 2007;133(2):554-9. UNOS registry report that highlights the interaction between increasing donor age and increasing ischaemic time as predictors of mortality post-heart transplant.

17. Ryan JB, Hicks M, Cropper JR, Garlick SR, Kesteven SH, Wilson $\mathrm{MK}$, et al. Functional evidence of reversible ischemic injury immediately after the sympathetic storm associated with experimental brain death. J Heart Lung Transplant: Off Publ Int Soc Heart Transplant. 2003;22(8):922-8.

18. Shivalkar B, Van Loon J, Wieland W, Tjandra-Maga TB, Borgers $\mathrm{M}$, Plets $\mathrm{C}$, et al. Variable effects of explosive or gradual increase of intracranial pressure on myocardial structure and function. Circulation. 1993;87(1):230-9.

19. Patarroyo M, Simbaqueba C, Shrestha K, Starling RC, Smedira N, Tang $\mathrm{WH}$, et al. Pre-operative risk factors and clinical outcomes associated with vasoplegia in recipients of orthotopic heart transplantation in the contemporary era. J Heart Lung Transplant: Off Publ Int Soc Heart Transplant. 2012;31(3):282-7.

20. Novitzky D, Cooper DK, Rosendale JD, Kauffman HM. Hormonal therapy of the brain-dead organ donor: experimental and clinical studies. Transplantation. 2006;82(11):1396-401.

21. Atkinson C, Floerchinger B, Qiao F, Casey S, Williamson T, Moseley E, et al. Donor brain death exacerbates complementdependent ischemia/reperfusion injury in transplanted hearts. Circulation. 2013;127(12):1290-9.

22. Gorlitzer M, Ankersmit J, Fiegl N, Meinhart J, Lanzenberger M, Unal K, et al. Is the transpulmonary pressure gradient a predictor for 
mortality after orthotopic cardiac transplantation? Transpl Int: Off J Eur Soc Organ Transplant. 2005;18(4):390-5.

23. Murali S, Kormos RL, Uretsky BF, Schechter D, Reddy PS, Denys $\mathrm{BG}$, et al. Preoperative pulmonary hemodynamics and early mortality after orthotopic cardiac transplantation: the Pittsburgh experience. Am Heart J. 1993;126(4):896-904.

24. Butler J, Stankewicz MA, Wu J, Chomsky DB, Howser RL, Khadim $\mathrm{G}$, et al. Pre-transplant reversible pulmonary hypertension predicts higher risk for mortality after cardiac transplantation. J Heart Lung Transplant: Off Publ Int Soc Heart Transplant. 2005;24(2):170-7.

25. Levin RL, Degrange MA, Bruno GF, Del Mazo CD, Taborda DJ, Griotti JJ, et al. Methylene blue reduces mortality and morbidity in vasoplegic patients after cardiac surgery. Ann Thorac Surg. 2004;77(2):496-9.

26. Young JB, Hauptman PJ, Naftel DC, Ewald G, Aaronson K, Dec $\mathrm{GW}$, et al. Determinants of early graft failure following cardiac transplantation, a 10-year, multi-institutional, multivariable analysis. J Heart Lung Transplant: Off Publ Int Soc Heart Transplant. 2001;20(2):212.

27. Stehlik J, Feldman DS, Brown RN, VanBakel AB, Russel SD, Ewald GA, et al. Interactions among donor characteristics influence post-transplant survival: a multi-institutional analysis. J Heart Lung Transplant. 2010;29(3):291-8.

28. Cosio Carmena MD, Gomez Bueno M, Almenar L, Delgado JF, Arizon JM, Gonzalez Vilchez F, et al. Primary graft failure after heart transplantation: characteristics in a contemporary cohort and performance of the RADIAL risk score. J Heart Lung Transplant: Off Publ Int Soc Heart Transplant. 2013;32(12):1187-95.

29. Boccheciampe N, Audibert G, Rangeard O, Charpentier C, Perrier JF, Lalot JM, et al. Serum troponin Ic values in organ donors are related to donor myocardial dysfunction but not to graft dysfunction or rejection in the recipients. Int J Cardiol. 2009;133(1):80-6.

30. Deibert E, Aiyagari V, Diringer MN. Reversible left ventricular dysfunction associated with raised troponin I after subarachnoid haemorrhage does not preclude successful heart transplantation. Heart. 2000;84(2):205-7.

31. Khush KK, Menza R, Nguyen J, Zaroff JG, Goldstein BA. Donor predictors of allograft use and recipient outcomes after heart transplantation. Circulation Heart failure. 2013;6(2):300-9.

32. Potapov EV, Wagner FD, Loebe M, Ivanitskaia EA, Muller C, Sodian R, et al. Elevated donor cardiac troponin T and procalcitonin indicate two independent mechanisms of early graft failure after heart transplantation. Int J Cardiol. 2003;92(2-3):163-7.

33. Deibert E, Barzilai B, Braverman AC, Edwards DF, Aiyagari V, Dacey R, et al. Clinical significance of elevated troponin I levels in patients with nontraumatic subarachnoid hemorrhage. J Neurosurg. 2003;98(4):741-6.

34. Ramaraj R, Sorrell VL, Movahed MR. Levels of troponin release can aid in the early exclusion of stress-induced (takotsubo) cardiomyopathy. Exp Clin Cardiol. 2009;14(1):6-8.

35. Dronavalli VB, Ranasinghe AM, Venkateswaran RJ, James SR, McCabe CJ, Wilson IC, et al. N-terminal pro-brain-type natriuretic peptide: a biochemical surrogate of cardiac function in the potential heart donor. Eur J Cardiothorac Surg: Off J Eur Assoc Cardiothorac Surg. 2010;38(2):181-6.

36. Lieppman K, Kramer-Clark L, Tobias JD. Plasma B-type natriuretic peptide monitoring to evaluate cardiovascular function prior to organ procurement in patients with brain death. Paediatr Anaesth. 2008;18(9):852-6.

37. McIlroy DR, Wallace S, Roubos N. Brain natriuretic peptide (BNP) as a biomarker of myocardial ischemia-reperfusion injury in cardiac transplantation. J Cardiothorac Vasc Anesth. 2010;24(6):939-45.

38. Vorlat A, Conraads VM, Jorens PG, Aerts S, Van Gorp S, Vermeulen T, et al. Donor B-type natriuretic peptide predicts early cardiac performance after heart transplantation. J Heart Lung Transplant: Off Publ Int Soc Heart Transplant. 2012;31(6):579-84.
39. Venkateswaran RV, Dronavalli V, Lambert PA, Steeds RP, Wilson IC, Thompson $\mathrm{RD}$, et al. The proinflammatory environment in potential heart and lung donors: prevalence and impact of donor management and hormonal therapy. Transplantation. 2009;88(4):582-8.

40. Aharinejad S, Andrukhova O, Gmeiner M, Thomas A, Aliabadi A, Zuckermann A, et al. Donor serum SMARCAL1 concentrations predict primary graft dysfunction in cardiac transplantation. Circulation. 2009;120(11 Suppl):S198-205.

41. Nicolas-Robin A, Salvi N, Medimagh S, Amour J, Le Manach Y, Coriat $\mathrm{P}$, et al. Combined measurements of $\mathrm{N}$-terminal pro-brain natriuretic peptide and cardiac troponins in potential organ donors. Intensive Care Med. 2007;33(6):986-92.

42. Weis F, Beiras-Fernandez A, Kaczmarek I, Sodian R, Kur F, Weis $\mathrm{M}$, et al. Levosimendan: a new therapeutic option in the treatment of primary graft dysfunction after heart transplantation. J Heart Lung Transplant: Off Publ Int Soc Heart Transplant. 2009;28(5):501-4.

43. Beiras-Fernandez A, Kur F, Kaczmarek I, Frisch P, Weis M, Reichart $\mathrm{B}$, et al. Levosimendan for primary graft failure after heart transplantation: a 3-year follow-up. Transplant Proc. 2011;43(6):2260-2.

44. Sundberg S, Antila S, Scheinin H, Hayha M, Virtanen M, Lehtonen L. Integrated pharmacokinetics and pharmacodynamics of the novel calcium sensitizer levosimendan as assessed by systolic time intervals. Int J Clin Pharmacol Ther. 1998;36(12):629-35.

45. Minev PA, El-Banayosy A, Minami K, Kortke H, Kizner L, Korfer R. Differential indication for mechanical circulatory support following heart transplantation. Intensive Care Med. 2001;27(8):1321-7.

46. Thomas HL, Dronavalli VB, Parameshwar J, Bonser RS, Banner NR, Steering Group of the UKCTA. Incidence and outcome of Levitronix CentriMag support as rescue therapy for early cardiac allograft failure: a United Kingdom national study. Eur J Cardiothorac Surg: Off J Eur Assoc Cardiothorac Surg. 2011;40(6):1348-54.

47. Ostadal P, Mlcek M, Holy F, Horakova S, Kralovec S, Skoda J, et al. Direct comparison of percutaneous circulatory support systems in specific hemodynamic conditions in a porcine model. Circ Arrhythmia Electrophysiol. 2012;5(6):1202-6.

48. Chamogeorgakis T, Rafael A, Shafii AE, Nagpal D, Pokersnik JA, Gonzalez-Stawinski GV. Which is better: a miniaturized percutaneous ventricular assist device or extracorporeal membrane oxygenation for patients with cardiogenic shock? ASAIO J. 2013;59(6): 607-11.

49. Taghavi S, Zuckermann A, Ankersmit J, Wieselthaler G, Rajek A, Laufer $\mathrm{G}$, et al. Extracorporeal membrane oxygenation is superior to right ventricular assist device for acute right ventricular failure after heart transplantation. Ann Thorac Surg. 2004;78(5):1644-9.

50. Aliabadi A, Groemmer M, Zimpfer D, Laufer G, Zuckermann A. Primary Graft Dysfunction Versus Primary Graft Failure: Are All Graft Problems Created Equal? Transpl Int. 2013;26:162.

51. Gomez-Bueno M, Barcelo JM, Segovia J, Cobo M, Mirelis J, Sufrate E, et al. Historical Trends of Primary Graft Failure after Heart Transplantation. J Heart Lung Transplant. 2009;28(2):S89.

52. Rosendale JD, Kauffman HM, McBride MA, Chabalewski FL, Zaroff JG, Garrity ER, et al. Aggressive pharmacologic donor management results in more transplanted organs. Transplantation. 2003;75(4):482-7.

53. Venkateswaran RV, Steeds RP, Quinn DW, Nightingale P, Wilson IC, Mascaro JG, et al. The haemodynamic effects of adjunctive hormone therapy in potential heart donors: a prospective randomized double-blind factorially designed controlled trial. Eur Heart J. 2009;30(14):1771-80.

54. Wheeldon DR, Potter CD, Oduro A, Wallwork J, Large SR. Transforming the "unacceptable" donor: outcomes from the adoption of a standardized donor management technique. J Heart Lung Transplant: Off Publ Int Soc Heart Transplant. 1995;14(4):734-42.

55. Zaroff JG, Rosengard BR, Armstrong WF, Babcock WD, D'Alessandro A, Dec GW, et al. Consensus conference report: maximizing use of organs recovered from the cadaver donor: 
cardiac recommendations, March 28-29, 2001, Crystal City, Va. Circulation. 2002;106(7):836-41.

56. Macdonald PS, Aneman A, Bhonagiri D, Jones D, O'Callaghan G, Silvester W, et al. A systematic review and meta-analysis of clinical trials of thyroid hormone administration to brain dead potential organ donors. Crit Care Med. 2012;40(5):1635-44. A systematic review of hormonal therapy administered to brain dead donors to enhance donor organ quality.

57. Demmy TL, Biddle JS, Bennett LE, Walls JT, Schmaltz RA, Curtis JJ. Organ preservation solutions in heart transplantation-patterns of usage and related survival. Transplantation. 1997;63(2):262-9.

58. Chambers DJ, Sakai A, Braimbridge MV, Kosker S, Manzanera G, Kind PR, et al. Clinical validation of St. Thomas' Hospital cardioplegic solution No. 2 (Plegisol). Eur J Cardiothorac Surg: Off J Eur Assoc Cardiothorac Surg. 1989;3(4):346-52.

59. Galinanes M, Murashita T, Hearse DJ. Long-term hypothermic storage of the mammalian heart for transplantation: a comparison of three cardioplegic solutions. J Heart Lung Transplant: Off Publ Int Soc Heart Transplant. 1992;11(4 Pt 1):624-35.

60. Menasche P, Termignon JL, Pradier F, Grousset C, Mouas C, Alberici G, et al. Experimental evaluation of Celsior, a new heart preservation solution. Eur J Cardiothorac Surg: Off J Eur Assoc Cardiothorac Surg. 1994;8(4):207-13.

61. Southard JH, Belzer FO. Organ preservation. Annu Rev Med. 1995;46:235-47.

62. Reichenspurner H, Russ C, Meiser BM, Uberfuhr P, Nollert G, Weinhold C, et al. University of Wisconsin solution for myocardial protection in heart transplantation-a comparison with HTK. Transplant Proc. 1993;25(6):3042-3.

63. Stehlik J, Edwards LB, Kucheryavaya AY, Aurora P, Christie JD, Kirk R, et al. The Registry of the International Society for Heart and Lung Transplantation: twenty-seventh official adult heart transplant report-2010. J Heart Lung Transplant: Off Publ Int Soc Heart Transplant. 2010;29(10):1089-103.

64. Watson AJ, Gao L, Sun L, Tsun J, Doyle A, Faddy SC, et al. Enhanced preservation of pig cardiac allografts by combining erythropoietin with glyceryl trinitrate and zoniporide. Am J Transplant: Off J Am Soc Transplant Am Soc Transplant Surg. 2013;13(7):1676-87.

65. Watson AJ, Gao L, Sun L, Tsun J, Jabbour A, Ru Qiu M, et al. Enhanced preservation of the rat heart after prolonged hypothermic ischemia with erythropoietin-supplemented Celsior solution. J
Heart Lung Transplant: Off Publ Int Soc Heart Transplant. 2013;32(6):633-40.

66. Kumarasinghe G, Iyer A, Watson A, Hicks M, Gao L, Doyle A, et al. Clinical experience supplementing celsior preservation solution with pro-survival kinase agents glyceryl trinitrate and erythropoietin demonstrates excellent myocardial recovery post cardiac transplantation. Transplantation. 2013;96(10):S259-60.

67. Rudd DM, Dobson GP. Eight hours of cold static storage with adenosine and lidocaine (Adenocaine) heart preservation solutions: Toward therapeutic suspended animation. J Thorac Cardiovasc Surg. 2011;142(6):1552-61.

68. Rudd DM, Dobson GP. Toward a new cold and warm nondepolarizing, normokalemic arrest paradigm for orthotopic heart transplantation. J Thorac Cardiovasc Surg. 2009;137(1): 198-207.

69. Tenderich G, Tsui S, El-Banayosy A, Dhital K, Schulte-Eistrup S, Schulz U, et al. The 1-year follow-up results of the PROTECT patient population using the organ care system. J Heart Lung Transplant. 2008;27(2):S166.

70. Esmailian F, Kobashigawa JA, Naka Y, Mancini D, Soltesz E, Hsich E, et al. The PROCEED II International Heart Transplant Trial with the Organ Care System Technology (OCS). J Heart Lung Transplant. 2013;32(4):S95-6.

71. Jayarajan SN, Taghavi S, Komaroff E, Mangi AA. Impact of low donor to recipient weight ratios on cardiac transplantation. J Thorac Cardiovasc Surg. 2013;146(6):1538-43.

72. Patel ND, Weiss ES, Nwakanma LU, Russell SD, Baumgartner WA, Shah AS, et al. Impact of donor-to-recipient weight ratio on survival after heart transplantation analysis of the United Network for Organ Sharing database. Circulation. 2008;118(14 suppl 1): S83-8.

73. Reed RM, Netzer G, Hunisicker L, Mitchell BD, Rajagopal K, Scharf S, et al. Cardiac Size and Sex-Matching in Heart Transplantation. J Am Coll Cardiol: Heart Fail. 2014;2(1):73-83.

74. Weiss ES, Allen JG, Patel ND, Russell SD, Baumgartner WA, Shah AS, et al. The impact of donor-recipient sex matching on survival after orthotopic heart transplantation: analysis of 18000 transplants in the modern era. Circ Heart Fail. 2009;2(5):401-8.

75. Dieleman JM, van Paassen J, van Dijk D, Arbous MS, Kalkman CJ, Vandenbroucke JP, et al. Prophylactic corticosteroids for cardiopulmonary bypass in adults. Cochrane Database Syst Rev. 2011;5, CD005566. 